\title{
Chapter 40 \\ Recapitulating the OECD-CRP Session \\ (Sponsored by the OECD's Co-operative \\ Research Program on Biological Resource \\ Management for Sustainable Agricultural \\ Systems)
}

\author{
Masa Iwanaga and Tomohiro Ban
}

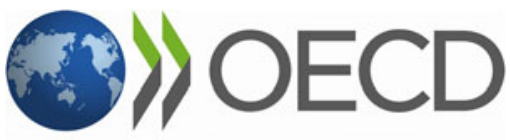

BETTER POLICIES FOR BETTER LIVES

The Special Session was sponsored by the OECD Co-operative Research Programme on Biological Resource Management for Sustainable Agricultural Systems, whose financial support made it possible for most of the invited speakers to participate in the Special Session.

In the specially arranged OECD Co-operative Research Program (CRP) sponsoredsession titled 'Sustainable food chain challenging for adaptation and mitigation to the climate change and global food security', six distinguished scientists in their respective field presented their latest scientific progress. Relevant sectors to the International Wheat Genetics Symposium, the Japanese Flour Millers Association and the Australian Grain Research and Development Corporation (GRDC), presented the actual demands and requirements of the wheat industry in the plenary

\footnotetext{
M. Iwanaga

Japan International Research Center for Agricultural Sciences,

1-1 Ohwashi, Tsukuba 305-8686, Japan

e-mail: miwanaga@affrc.go.jp

T. Ban $(\bowtie)$

Kihara Institute for Biological Research, Yokohama City University, 641-12 Maioka, Yokohama 244-0813, Japan

e-mail: tban@yokohama-cu.ac.jp 
talks. Status and movement of the two international wheat science initiatives, the International Wheat Conference (IWC) and the Wheat Initiative (WI), were introduced and future interactions and compilation necessary to encourage the wheat science society in the area of wheat genomics/post-genomics were discussed. The section, 'Enhancing relevance and efficiency of wheat science for the society' recapitulated the scientific approaches to and the socio-economical relevance/efficiency of wheat science vital to drafting an action plan by the international wheat science society.

\section{Aim of This Session and Its Relation with OECD-CRP}

Wheat is the most widely grown staple food crop in the world. IWGS has been promoting the latest research outcomes and discussions on wheat genetics, breeding and biodiversity in order to contribute to the better understanding of the food chain issues. Worldwide food crisis and climate change, which adversely affect the food chain are common threats to all humankind. IWGS has endeavored to lead wheat research for development to save the world from starvation just like what the Green Revolution had done. The OECD members are on the verge of a phase to concentrate the wisdom of science in an attempt to challenge these global threats at the coming of age of wheat genomics. IWGS can open windows for sustaining links of international collaborative research covering the topics under the OECD-CRP research theme 'The Food Chain'.

Wheat is a major renewable resource for food, feed and industrial raw material, and is among the major crops of the OECD countries. It is the most widely cultivated cereal worldwide, covering over 200 million ha of agricultural lands and the second most abundant staple crop for humankind; it is also an important commodity crop for the OECD countries. We should address the challenge to double its yield in the coming half century to meet the food requirement as calorie intake of the growing global population. At the same time, we should preserve the earth environment conserving the biodiversity for sustainability, food hygiene and energy production. G20 Agriculture Ministers met in Paris on June 22nd-23rd, 2011 and agreed to formulate the Ministerial Declaration on 'Action Plan on Food Price Volatility and Agriculture'. It issued a statement to tackle the threats to increasing sustainable wheat production, and to promote the Wheat Initiative (WI) which reinforces synergies between national and international wheat research programs. IWGS will be a great opportunity to launch international discussions and actions towards recommending a direction for food chain policies. 


\section{Major Highlights of the Presentations}

\section{Part 1: Wheat Research for Sustainable Food Chain for Climate Change and Global Food Security}

(Distinguished scientists in their respective field presented their latest scientific progress with perspectives for relevant wheat research and development)

1. Matthew P Reynolds (CIMMYT, Mexico), 'Exploring genetic resources to increase adaptation of wheat to climate change'

- Seamless flow: Crop design to breeding

- Whole plant (roots, spike etc.)

- Genetic resources represent a vast and largely untapped opportunity

- Innovative phenotyping (roots, air, etc.) for targeted environments is key to effective use of genetic resources

- Transgenes look promising but need to be evaluated in elite backgrounds

- Strategic trait-based use of well-characterized genetic resources achieves cumulative gene actions for yield potential (strategic, analytical crop improvement)

2. Beat Keller (Univ. of Zurich, Switzerland), 'Genomic approaches towards durable fungal disease resistance in wheat'

- Durable resistance (host-pathogen dynamic interactions)

- Characterization of the molecular basis of resistance gene function and specificity $>$ develop a more durable type resistance based on major genes

- Gene cloning and transgene research approach

- Successful field trial (field tolerance)

3. Z. Li, presented by Xueyong Zhang (CAAS, China), 'New progress in wheat wide hybridization for improving the resistance to biotic and abiotic stresses'

- Great Chinese history of wheat breeding, responding to changing needs such as yield, quality, salt tolerance, drought tolerance, Ug99 (Xiaoyan 6-81, Hexaploids)

- Wisdom from the past experience for the future (addressing climate change; biotic and abiotic stresses)

(i) Wide adaptation by germplasm with a wide genetic background (including alien spp. introgression)

(ii) Extensive nurseries/trials in multi-environments

4. Michael Baum (ICARDA, Jordan), 'Global crop improvement networks to bridge technology gaps'

- The International Wheat Improvement Network (IWIN) results in the development of both germplasm and human resources

- It has sustained increase of wheat production \& productivity $>$ food security and farmer's livelihood 
- Current contribution of IWIN > breeding, genetic gain \& future role under difficult circumstances

(i) New locations/shuttle breeding

(ii) FIGS (for stem rust, septoria, etc.)

(iii) Major progress for $\mathrm{Ug} 99$ in the region, etc.

5. Mark Sorrells (Cornell Univ., USA), 'Genomic selection in plants: Empirical results and implications for wheat breeding'

- GS differs from MAS and Association Breeding in that the underlying genetic control and biological function is not necessarily known; complementing other breeding methods

- GS preserves the creative nature of phenotypic selection to sometimes arrive at solutions outside the engineer's scope

- Integrating environmental covariates and crop modeling into the genomic selection framework to predict $\mathrm{G}^{*} \mathrm{E}$ increases prediction accuracy and provides insight into the genetic architecture controlling $G^{*} E$

- Most important advantages are reductions in the length of the selection cycle resulting in greater genetic gain per year

6. Rowan Mitchell (Rothamsted Research, UK), 'Wheat genes or enhanced human nutrition'

- Dietary fibre (DF) in wheat flour is derived from cell wall of the starch endosperm $>$ composed $(\sim 70 \%)$ of the polysaccharide arabinoxylan (AX) which is abundant in grasses such a wheat

- Candidate genes were identified > Glycosyl transferase (GT43, 47, 61) for AX synthesis

- QTLs for high DF from 'Yumai34' identified

- Molecular understanding of the AX synthesis (including transgene research) will help to identify the casual alleles of the QTLs $>$ accelerate the introduction of high fibre alleles into modern commercial cultivars.

\section{Part 2: Enhancing Relevance and Efficiency of Wheat Science for the Society}

7. Koji Murakami (Nisshin Flour Milling Inc., Japan), 'What does wheat flour industry expect from wheat science?'

- The Evolution of Grain Quality from the Miller's Perspective

- Japanese special requirement for wheat is 'Uniformity and Safety' for good product

- Researchers' voice on supporting public research from the private sectors? 
8. Francis Ogbonnaya (GRDC, Australia), 'What does industry seed sector expect from wheat science?'

- Australian wheat industry > Export focused

- Research outputs which support and grow market position = reliability of supply

(i) Volume - yield potential and stability

(ii) Quality - of the grain and in the grain

(iii) Yield stability - disease resistance/ temperature tolerance/ Soil toxicity tolerance

(iv) Reduced input costs $>$ better use of fertilizers (NUE, PUE)

- Government-Research-Industry-Growers-International linkages

9. Hans J. Braun (CIMMYT, Mexico), 'Improving wheat for world food security: Concerted approach of IWGS and International Wheat Conference (IWC)', and

10. Peter Lngridge (Univ. of Adelaide, Australia), 'Wheat Initiative (WI) for sustainable food chain'

- Major importance and many challenges (still underinvested!!)

- Status of the two international wheat science initiatives (IWGS, IWC)

- Showing the opportunity for further international collaboration (WI) including Working Groups!

\section{Outcomes/Conclusions in Terms of Policy Relevance}

The 12th IWGS concluded with perspectives on wheat genetics/breeding including one stating that in-depth disciplinary research should combine with inter-disciplinary approaches and international collaborations for enhanced social impact. Research outputs that support and strengthen market position and increase reliability of supply will be recommended by policy makers who act on Government-ResearchIndustry-Growers-International linkages. Overall outcomes from the 12th IWGS included new approaches for production of valuable and safe materials and substances for the sustainable production of wheat as a staple food for the world. International researchers exchanged information on their latest researches on wheat genetics, genomics, gene function, evolution, genetic resources, and breeding for sustainable wheat production. Research outcomes on genome sequence information and transgenic plants were discussed. The major highlights distilled common threads, developed a coherent story, and added to the climax of the 12th IWGS focusing on wheat research for a sustainable food chain in the midst of challenging global climate change.

Open Access This chapter is distributed under the terms of the Creative Commons Attribution Noncommercial License, which permits any noncommercial use, distribution, and reproduction in any medium, provided the original author(s) and source are credited. 